\title{
$11^{\circ}$ Congresso Brasileiro de Inovação e Gestão de
}

Desenvolvimento do Produto

\section{PLANEJAMENTO ESTRATÉGICO E PROJETO INFORMACIONAL DO DUAL CASE: UM PROJETO DE DESENVOLVIMENTO DE UM NOVO ESTOJO PARA ÓCULOS}

Adriana Georgia Borges Soares (adrianageorgia@hotmail.com) - Departamento De Ciências Exatas, Tecnológicas e Humanas, Universidade Federal Rural do Semi Árido.

Daniela Cristina de Sousa Silva (ssousadaniela@gmail.com) - Departamento De Ciências Exatas, Tecnológicas e Humanas, Universidade Federal Rural do Semi Árido.

Társila Cavalcante Bezerra (tarsilabezerra@hotmail.com) - Departamento De Ciências Exatas, Tecnológicas e Humanas, Universidade Federal Rural do Semi Árido.

Samira Yusef Araújo de Falani (samira.yusef@ufersa.edu.br) - Departamento De Ciências Exatas, Tecnológicas e Humanas, Universidade Federal Rural do Semi Árido.

\section{RESUMO}

O presente trabalho objetiva expor as etapas de geração da ideia e o processo decisório para a escolha do produto desenvolvido, até a definição das principais características de um estojo para dois óculos, nomeado de Dual Case, que foi desenvolvido em sala de aula na disciplina de Projeto de Desenvolvimento de Produto utilizando a metodologia de Rozenfeld et al. (2006). O trabalho iniciou-se com a etapa de planejamento estratégico do produto, por meio da aplicação da ferramenta Brainstorming, onde os autores listaram a maior quantidade de ideias possíveis, em seguida, estas foram registradas e filtradas para serem consideradas as mais relevantes e viáveis para a realidade dos envolvidos. Em seguida, ocorreu a aplicação no Método Score, que se fez necessário para decidir qual dos produtos resultantes do Brainstorming seria desenvolvido. O projeto informacional iniciou com a identificação dos possíveis clientes e aplicação de um questionário qualitativo, elaborado pela equipe desenvolvedora e aplicado por meio Google Formulário, para coletar as possíveis características do produto, obtendo 39 respostas. Com as informações do primeiro questionário, foi possível a construção da árvore da qualidade demandada, que organiza as respostas em características do produto primária e secundária e definição das perguntas do segundo questionário, que resultou na identificação do grau de importância de cada característica mencionada pelos possíveis clientes no primeiro questionário, na qual se obteve 31 respostas. Com isso, foi realizada a análise do índice de importância corrigido pela qualidade demandada e priorizadas as características que devem existir no Dual Case para serem transformadas em especificações meta para o produto. Face ao exposto, o projeto resultou em um estojo que comporta dois óculos, com uma divisória ao meio e espelho acoplado. O tamanho meta foi definido em aproximadamente $16 \mathrm{~cm} \times 10 \mathrm{~cm}$, seu material externo em couro e revestimento interno aveludado.

Palavras-chave: Projeto de desenvolvimento de produto, Dual case, planejamento estratégico de produtos, projeto informacional. 


\section{INTRODUÇÃO}

Em decorrência da globalização e como consequência o avanço tecnológico, o atual cenário empresarial se encontra em circunstâncias de elevada competitividade. Desse modo, inovação e qualidade são essenciais a todos que pretendem se destacar no mercado, tendo em vista o alto grau de exigência dos consumidores.

Nesse contexto, um dos principais fatores de competividade nos últimos anos é o processo de desenvolvimento de produtos, que é tido como um diferencial para empresas de diversossetores e tamanhos, adaptando-se às características de cada uma, buscando a constante inovação dos seus produtos, desde a idealização até o aperfeiçoamento e venda destes. Todavia, um produto novo requer um planejamento bem elaborado e estruturado que descreva de forma detalhada todas as fases de planejamento e execução, além do mapeamento das necessidades dos clientes, para que sua eficácia seja garantida.

De acordo com Rozenfeld et al. (2006) desenvolver produtos é um conjunto de atividades que visam chegar às especificações de projeto de um produto e de seu processo de produção, a partir das necessidades do mercado, das possibilidades e restrições tecnológicas, considerando estratégias competitivas e de produto da empresa, para que assim a manufatura seja capaz de produzi-lo.

Dessa forma, este trabalho objetiva expor as etapas de desenvolvimento de um novo produto, a partir da metodologia de Rozenfeld et al. (2006), desde a geração da ideia, o processo decisório para a escolha do produto, até a definição das principais características de um estojo para dois óculos, nomeado de Dual Case.

\section{PROCESSO DE DESENVOLVIMENTO DE NOVOS PRODUTOS}

O Processo de Desenvolvimento de Produto (PDP) é o processo que transforma as necessidades e requisitos dos clientes em especificações para que um produto e o seu processo de produção possam ser executados. O PDP é um dos processos mais importantes para o negócio de uma empresa, uma vez que, através dele que a empresa é capaz de criar novos produtos mais competitivos e em menor tempo, com a finalidade de atender à constante evolução do mercado (ROSENFELD et al., 2006).

O PDP é composto por em três macro fases, o Pré-desenvolvimento, Desenvolvimento e Pósdesenvolvimento. Estas, por sua vez, são divididas em fases, atividades e tarefas necessárias para o desenvolvimento de produtos. Nesse trabalho, foram abordadas a macro fase de Prédesenvolvimento com a etapa do Planejamento Estratégico de Produtos e a macro fase de Desenvolvimento envolvendo a fase do Projeto Informacional.

\subsection{Planejamento estratégico de produtos}

De acordo com Freitas et al. (2014), o Planejamento Estratégico de Produtos consiste na etapa inicial de preparação e planejamento para o desenvolvimento do produto com base em análises preliminares de tecnologia e mercado, traduzindo no portfólio de produtos da empresa e o seu alinhamento com os objetivos estratégicos da organização. Esta etapa também envolve o planejamento de cada projeto de produto individual conforme as abordagens de gerenciamento de projetos.

O objetivo do Planejamento Estratégico de Produtos é retificar o plano estratégico de negócios, garantindo a adequação entre as limitações de recursos da empresa e os requisitos dos clientes, verificando a viabilidade no portfólio do produto e dar início do planejamento de um produto 
(ROSENFELD et al., 2006). Para esse fim, utiliza-se a ferramenta Brainstorming, que segundo Abrantes (2016), é uma técnica de criatividade que pode oferecer idéias para a construção de uma nova solução, ou seja, um novo produto. Utiliza-se também, o método score, uma ferramenta que usa um conjunto de critérios predefinidos, baseando-se em notas para avaliar os produtos do portfólio e decidir o projeto de produto que será desenvolvido (TAINO, 2008).

\subsection{Projeto Informacional}

O Projeto Informacional é determinado por um conjunto de requisitos para transformar-se em especificações de projeto. Essas especificações elaboradas durante o projeto informacional são transformadas em características do produto, atendendo assim, as necessidades dos clientes (ROSENFELD et al., 2006).

A partir de um levantamento detalhado de informações, conforme Freitas et al. (2014), o Projeto Informacional tem como objetivo estabelecer as especificações-meta do produto, um conjunto de requisitos mensuráveis e informações qualitativas adicionais que refletem como as necessidades dos clientes serão atendidas de uma forma ideal. Para atender ao objetivo do projeto informacional, são necessárias pesquisas de mercado e análise dos dados, como o cálculo do índice de importância corrigido pela qualidade demandada.

\section{METODOLOGIA}

O projeto do produto segue a metodologia proposta por Rozenfeld et al. (2006), que consiste em três macro fases, o pré-desenvolvimento que é a etapa inicial de preparação e planejamento para o desenvolvimento do produto, o desenvolvimento, consiste em etapas mais detalhadas para construção do produto, como projeto informacional, projeto conceitual, projeto detalhado, preparação para produção e lançamento do produto, e o pós- desenvolvimento, agrupa a fase de acompanhar produto e processo e a fase de descontinuar o produto. Para esse trabalho, foram abordadas as duas primeiras macro fases, sendo exploradas as etapas de planejamento estratégico do produto e o projeto informacional

Primeiramente foi aplicada a ferramenta brainstorming. Segundo Godoy (2001) esta técnica propõe que um grupo de pessoas compartilhem e discutam ideias de maneira disciplinada, para que possam chegar a um consenso com objetivo de conseguir extrair ideias de produtos inovadores, que poderiam ser desenvolvidos como projeto de produto para a disciplina de Projeto de Desenvolvimento de Produtos. Assim, todas as ideias foram devidamente registradas, agrupadas por categorias e, então selecionadas as que possuíam maior equilíbrio entre relevância e viabilidade.

Para a escolha final do produto a ser desenvolvido, foi aplicado o Método Score, que consiste na definição de critérios e seus pesos para a atribuição de notas aos possíveis produtos a serem desenvolvidos. Uma vez definido o produto a ser desenvolvido, foi imprescindível pesquisar no banco de dados do Instituto Nacional de Propriedade Intelectual (INPI) a existência do produto para não desenvolver um produto já registrado.

Em seguida foi aplicado, via Google Formulário, um questionário qualitativo a clientes em potencial com o objetivo de obter informações sobre as características esperadas para o produto de forma subjetiva. Esta pesquisa obteve um total de 39 respondentes.

Com base nas informações obtidas no questionário qualitativo, foi possível a elaboração da árvore da qualidade demandada. Nesta etapa, as respostas dos potenciais clientes foram classificadas em características primárias e secundárias do produto, servindo de fonte de informação para definir os itens do segundo questionário aplicado. 
Um novo questionário, dessa vez quantitativo, foi aplicado afim de se saber o grau de importância das características respondidas no questionário qualitativo. Assim foi possível calcular o índice de importância corrigido pela qualidade demandada, que relaciona as características requisitadas pelos clientes, avaliando-as estrategicamente pela equipe do projeto e competitivamente, relacionando as características requisitadas pelos clientes a produtos concorrentes, recomendando-se a utilização de uma escala de importância definida antecipadamente para auxiliary a avaliação feita pelo cliente (RIBEIRO; MOTTA, 1996). Por fim, com base nas informações obtidas, foi possível idealizar a forma do produto através de um desenho preliminar elaborado no software AutoCAD2007®.

\section{PROCESSO DE DESENVOLVIMENTO DO ESTOJO PARA DOIS ÓCULOS}

\subsection{Uso da ferramenta Brainstorming}

O Brainstorming foi aplicado com os envolvidos no projeto de desenvolvimento do novo produto para a geração de ideias de novos produtos que deixassem a rotina dos envolvidos mais prática. A princípio, as ideias propostas foram: almofada com massageador, batom com pó facial acoplado, escova de cabelo que alisa, batom com pó facial e lápis acoplados, pen drive com caixa de som, esmalte colorido com fortalecedor de unhas, cílios postiços com cola já inclusa, coletor de brinquedos com imã, tênis aromatizado, estojo para dois óculos, pen drive com duas entradas, pen drive com mini USB para usar pelo celular, batom com pó compacto e rímel, capinha de celular duplo.

O próximo passo foi agrupar essas ideias e escolher as que possuíam menos restrições de recursos tecnológicos, materiais e mão de obra, ou seja, as ideias que seriam mais viáveis de desenvolver, fazendo assim um refinamento, onde o objetivo seria criar um produto novo para o mercado. Nesse caso, foram escolhidas as ideias: estojo para dois óculos, cílios com cola já inclusa, batom com pó compacto e rímel e coletor de brinquedos com imã.

\subsection{Aplicação do modelo baseado em notas ou Método Score}

O método score permite aos responsáveis pelo projeto, analisar qual produto será selecionado para ser desenvolvido. Primeiramente foi necessário definir os critérios para a análise, que no caso foram: viabilidade econômica, mão de obra especializada, disponibilidade de matériaprima, aceitação no mercado, tecnologia, design e flexibilidade de expansão.

A equipe relacionou cada um dos critérios entre si atribuindo o grau de importância, para então ser definido o peso para cada índice, indicando o nível de importância de cada critério. A equipe em conjunto atribuiu notas que variavam de 0 - Menos Importante, 1 - Igual Importância e 2 Mais Importante. Os resultados apontaram os seguintes pesos, conforme apresentado na figura 1. 
Figura 1: Resultado do relacionamento entre os critérios de escolha do projeto. Fonte: Os autores (2017).

\begin{tabular}{|c|c|c|c|c|c|c|c|c|}
\cline { 2 - 9 } \multicolumn{1}{c|}{} & $\begin{array}{c}\text { Viabilidade } \\
\text { econômica }\end{array}$ & $\begin{array}{c}\text { Mão de obra } \\
\text { especializada }\end{array}$ & $\begin{array}{c}\text { Matéria } \\
\text { prima } \\
\text { disponível }\end{array}$ & $\begin{array}{c}\text { Aceitação } \\
\text { no } \\
\text { mercado }\end{array}$ & Tecnologia & Design & $\begin{array}{c}\text { Flexibilidade } \\
\text { de expansão }\end{array}$ & Peso \\
\hline $\begin{array}{c}\text { Viabilidade } \\
\text { econômica }\end{array}$ & - & 2 & 1 & 1 & 2 & 2 & 2 & 10 \\
\hline $\begin{array}{c}\text { Mão de obra } \\
\text { especializada }\end{array}$ & 0 & - & 0 & 0 & 1 & 2 & 0 & $\mathbf{3}$ \\
\hline $\begin{array}{c}\text { Matéria } \\
\text { prima } \\
\text { disponível }\end{array}$ & 1 & 2 & - & 1 & 1 & 2 & 2 & 9 \\
\hline $\begin{array}{c}\text { Aceitação no } \\
\text { mercado }\end{array}$ & 1 & 2 & 1 & - & 2 & 2 & 2 & $\mathbf{1 0}$ \\
\hline Tecnologia & 0 & 1 & 1 & 0 & - & 2 & 1 & $\mathbf{5}$ \\
\hline Design & 0 & 0 & 0 & 0 & 0 & - & 0 & $\mathbf{0}$ \\
\hline $\begin{array}{c}\text { Flexibilidade } \\
\text { de expansão }\end{array}$ & 0 & 2 & 0 & 0 & 1 & 2 & - & $\mathbf{5}$ \\
\hline
\end{tabular}

A partir desse momento cada integrante da equipe de projeto fez a sua avaliação de forma individual em relação cada um dos três possíveis projetos escolhidos no brainstorming. As notas foram atribuídas de 1 a 5 para cada critério, onde 1 representa menor desempenho do produto no critério e 5 o maior desempenho. Calculou-se ainda a média das notas paraidentificar o desempenho do produto em cada critério, sendo expressa de acordo com a equação 1 .

\section{Média de avaliação $=\frac{2 \mathrm{i}}{\mathbf{n}}($ Equaçăo 1)}

Onde i é a nota do critério dada por cada membro da equipe e n é a quantidade membros da equipe. As figuras de 2 a 5 apresentam as médias obtidas de cada produto.

Figura 2: Método score para avaliação do produto estojo para dois óculos. Fonte: Os autores (2017).

\begin{tabular}{|c|c|c|c|c|c|c|c|}
\hline \multicolumn{8}{|c|}{ Estojo para dois óculos } \\
\hline & $\begin{array}{l}\text { Viabilidade } \\
\text { econômica }\end{array}$ & $\begin{array}{l}\text { Mão de obra } \\
\text { especializada }\end{array}$ & $\begin{array}{c}\text { Matéria } \\
\text { prima } \\
\text { disponivel }\end{array}$ & \begin{tabular}{|c|} 
Aceitação \\
do \\
mercado
\end{tabular} & Tecnologia & Design & $\begin{array}{c}\text { Flexibilidade e } \\
\text { expansão }\end{array}$ \\
\hline Desenvolvedor 1 & 5 & 4 & 5 & 5 & 4 & 2 & 4 \\
\hline Desenvolvedor 2 & 5 & 4 & 5 & 5 & 4 & 2 & 3 \\
\hline Desenvolvedor 3 & 5 & 4 & 5 & 5 & 4 & 1 & 4 \\
\hline Média & $\overline{5}$ & 4 & 5 & 5 & 4 & 1,6667 & 3,667 \\
\hline
\end{tabular}

Figura 3: Método score para avaliação do produto Cílios com cola. Fonte: Os autores (2017).

\begin{tabular}{|l|r|r|r|r|r|r|r|} 
& \multicolumn{9}{c|}{ Cílios com cola } & Matéria & $\begin{array}{c}\text { Aceitação } \\
\text { do } \\
\text { prima } \\
\end{array}$ & $\begin{array}{c}\text { Viabilidade } \\
\text { econômica }\end{array}$ & $\begin{array}{c}\text { Mão de obra } \\
\text { especializada }\end{array}$ & $\begin{array}{c}\text { primado } \\
\text { disponivel }\end{array}$ & Tecnologia & Design & $\begin{array}{c}\text { Flexibilidade e } \\
\text { expansão }\end{array}$ \\
\hline Desenvolvedor 1 & 4 & 5 & 2 & 5 & 3 & 5 & 1 \\
\hline Desenvolvedor 2 & 3 & 4 & 4 & 5 & 4 & 5 & 3 \\
\hline Desenvolvedor 3 & 5 & 4 & 3 & 5 & 3 & 5 & 3 \\
\hline Média & 4 & 4,33 & 3 & 5 & 3,33 & 5 & 2,33 \\
\hline
\end{tabular}


Figura 4: Método score para avaliação do produto pó com batom e rímel. Fonte: Os autores (2017).

\begin{tabular}{|c|c|c|c|c|c|c|c|}
\hline \multicolumn{8}{|c|}{ Pó com batom e rímel } \\
\hline & $\begin{array}{l}\text { Viabilidade } \\
\text { econômica }\end{array}$ & $\begin{array}{l}\text { Mão de obra } \\
\text { especializada }\end{array}$ & \begin{tabular}{c|} 
Matéria \\
prima \\
disponível
\end{tabular} & \begin{tabular}{|c|}
$\begin{array}{c}\text { Aceitação } \\
\text { do } \\
\text { mercado }\end{array}$ \\
\end{tabular} & Tecnologia & Design & $\begin{array}{c}\text { Flexibilidade e } \\
\text { expansão }\end{array}$ \\
\hline Desenvolvedor 1 & 3 & 3 & 3 & 5 & 3 & 1 & 2 \\
\hline Desenvolvedor 2 & 3 & 4 & 4 & 5 & 3 & 2 & 2 \\
\hline Desenvolvedor 3 & 3 & 3 & 3 & 3 & 3 & 1 & 3 \\
\hline Média & 3 & 3,33 & 3,33 & 4,33 & 3 & 1,33 & 2,33 \\
\hline
\end{tabular}

Figura 5: Método score para avaliação do coletor de brinquedos com imã. Fonte: Os autores (2017).

\begin{tabular}{|c|c|c|c|c|c|c|c|}
\hline & $\begin{array}{l}\text { Viabilidade } \\
\text { econômica }\end{array}$ & $\begin{array}{l}\text { Mão de obra } \\
\text { especializada }\end{array}$ & $\begin{array}{c}\text { Matéria } \\
\text { prima } \\
\text { disponivel }\end{array}$ & \begin{tabular}{|c|} 
Aceitação \\
do \\
mercado
\end{tabular} & Tecnologia & Design & $\begin{array}{c}\text { Flexibilidade e } \\
\text { expansão }\end{array}$ \\
\hline Desenvolvedor 1 & 2 & 3 & 2 & 4 & 2 & 4 & 3 \\
\hline Desenvolvedor 2 & 2 & 4 & 3 & 3 & 3 & 4 & 3 \\
\hline Desenvolvedor 3 & 4 & 4 & 2 & 3 & 3 & 3 & 3 \\
\hline Média & 2,66 & 3,67 & 2,33 & 3,33 & 2,67 & 3,67 & 3 \\
\hline
\end{tabular}

De posse das médias das notas de cada critério, foi calculada a média ponderada pelos pesos definidos na figura 1, para analisar a ordem de prioridade dos projetos de produtos a serem desenvolvidos. A média ponderada foi dada pela equação 2 .

$$
\frac{\text { Peso : Média }}{\text { Epeso }}(\text { Equaçato 2) }
$$

Figura 6. Resultado do método score.Fonte: Os autores (2017).

\begin{tabular}{|c|c|c|c|c|}
\cline { 2 - 5 } \multicolumn{1}{c|}{} & $\begin{array}{c}\text { Estojo para } \\
\text { dois óculos }\end{array}$ & Cílios com cola & $\begin{array}{c}\text { Pó com batom } \\
\text { e rímel }\end{array}$ & $\begin{array}{c}\text { Coletor de } \\
\text { brinquedos } \\
\text { com imã }\end{array}$ \\
\hline $\begin{array}{c}\text { Média } \\
\text { ponderada }\end{array}$ & 4,5814 & 3,7984 & 3,2868 & 2,8837 \\
\hline
\end{tabular}

De acordo com os resultados encontrados, a partir da aplicação do método score, foi possível definir que o produto a ser desenvolvido seria o estojo para dois óculos.

\subsection{Pesquisa no banco de patentes}

Após a aplicação do método score, foi realizada uma pesquisa no site do Instituto Nacional de Propriedade Industrial- INPI, para verificar a inexistência de produtos já patenteados no Brasil que tenham a mesma finalidade, e após a realização da pesquisa, pode-se concluir que ainda não há no Brasil nenhum produto similar ao estojo para dois óculos, tornando a possibilidade do desenvolvimento de um novo produto para o mercado.

\subsection{Aplicação do questionário qualitativo}

O projeto informacional transforma a informações das necessidades dos potenciais clientes em requisitos de projeto e especificações meta para o produto. Nessa fase, elaborou-se um questionário qualitativo com perguntas subjetivas onde o cliente informava suas necessidades quanto as principais características deveriam conter em um estojo para óculos. O questionário foi aplicado no Google Formulários, que inicialmente perguntava se o respondente utilizava ou carregava dois óculos ou não.

Posteriormente, ao o respondente se classificar como utilizadores de dois óculos, os entrevistados respondiam as perguntas listadas na figura 7 com o objetivo de obter informações acerca das características das partes que deviam compor o produto e das necessidades dos 
potenciais clientes.

Figura 7: Questionário qualitativo. Fonte: Os autores (2017).

\begin{tabular}{|l|l|}
\hline Descrição da pesquisa & $\begin{array}{l}\text { Somos alunas do curso de Engenharia } \\
\text { de Produção da UFERSA campus- } \\
\text { Angicos/RN, cursando a disciplina de } \\
\text { Projeto e Desenvolvimento do Produto. } \\
\text { Estamos realizando uma pesquisa para } \\
\text { saber sua opinião sobre um produto } \\
\text { novo para o mercado, um estojo com } \\
\text { capacidade para comportar dois óculos. } \\
\text { Suas informações vão nos ajudar a } \\
\text { entender suas necessidades. }\end{array}$ \\
\hline Sexo: & Feminino ( ) \\
\hline Idade: ( ) 15-25 ( ) 26-35 ( ) 36-45 ( ) Acima de 45 \\
\hline 1. Você utiliza mais de um óculos diariamente? \\
\hline 2. Como você faz para guardar os dois óculos? \\
\hline 3. Você se interessaria em estojo duplo para óculos? \\
\hline 4. Como você gostaria que ele fosse (tamanho, design, preferência por cor, etc). \\
\hline 5. Que tipo de material deveria ser o estojo? \\
\hline 6. Além de armazenar os óculos, ele poderia ter outra função? \\
\hline 7. Em que situações do dia a dia ele seria utilizado? \\
\hline
\end{tabular}

As respostas do questionário qualitativo proporcionaram a classificação das características e requisitos dos clientes quanto aos níveis primários e secundários, permitindo a construção da árvore da qualidade demandada, conforme apresentado na figura 8.

Figura 8: Árvore da Qualidade Demandada. Fonte: Os autores (2017).

\begin{tabular}{|l|l|}
\hline NÍVEL PRIMÁRIO & NÍVEL SECUNDÁRIO \\
\hline \multirow{4}{*}{ Cor } & Preta \\
\hline \multirow{4}{*}{ Formato } & Cores Claras \\
\cline { 2 - 2 } & Qualquer cor \\
\hline \multirow{4}{*}{ Material } & Quadrado \\
\cline { 2 - 2 } & Cilindro \\
\cline { 2 - 2 } & Estojos Convencionais \\
\hline \multirow{4}{*}{ Revestimento } & Other \\
\cline { 2 - 2 } & Couro \\
\cline { 2 - 2 } & Plástico \\
\cline { 2 - 2 } & Acrilico \\
\hline Funcionalidade & Silicone \\
\cline { 2 - 2 } & Aveludado \\
\cline { 2 - 2 } & Tecido \\
\cline { 2 - 2 } & Espuma \\
\hline & Emborrachado \\
\cline { 2 - 2 } & Espelho na parte interna \\
\cline { 2 - 2 } & Bolso para guardar dinheiro \\
\hline & Anexo para lentes de contato \\
\hline
\end{tabular}

A árvore da qualidade demandada proporcionou a organização de diversas informações sobre as necessidades dos clientes, que permitiram a elaboração do questionário quantitativo, contendo informações compiladas que passariam a ser classificadas de acordo com o grau de importância dado pelos potenciais clientes.

\subsection{Aplicação do questionário quantitativo}

O questionário quantitativo foi elaborado a fim de mensurar a importância de cada requisito secundário. O novo questionário foi aplicado apenas a utilizadores de dois óculos e de diversas idades, com características e requisitos relacionados e analisados anteriormente. O questionário foi aplicado por meio do Google Formulários, onde se obtiveram 31 respostas classificando as características acerca do seu grau de importância.

Cada requisito recebeu uma pontuação de importância pelos potenciais clientes respondentes e para tratamento e análise dos dados, a equipe desenvolvedora do produto fez a avaliação competitiva e estratégica de cada requisito, assim pôde-se encontrar o Índice de Importância Corrigido da Qualidade Demandada - IDi* de cada característica do produto, composto pela 
fórmula contida na equação 3.

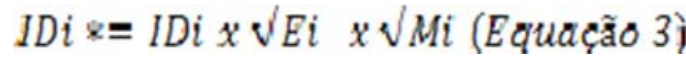

Sendo:

$\mathrm{IDi}^{*}=$ Índice de importância corrigido da qualidade demandada IDi $=$ Importância dos itens definida pelos potenciais clientes

$\mathrm{Ei}=$ Avaliação estratégica dos itens da qualidade demandada $\mathrm{Mi}=$ Avaliação competitiva dos itens da qualidade demandada

Para esse cálculo foram necessários os tratamentos nos dados, obtendo a média de importância atribuída pelos respondentes, o que foi chamado na figura 9 de Peso Relativo ou IDi. Os índices Ei e Mi foram determinados a partir da análise estratégica e competitiva, respectivamente. As notas foram atribuídas pelos próprios desenvolvedores a partir da análise da importância de cada demanda para a equipe, estrategicamente, e frente a produtos similares concorrentes, competitivamente.

Figura 9: Análise da importância corrigida pela qualidade demandada. Fonte: Os autores (2017).

\begin{tabular}{|c|c|c|c|c|c|c|}
\hline $\begin{array}{c}\text { Demanda da } \\
\text { qualidade }\end{array}$ & Média & $\begin{array}{l}\text { Soma dos } \\
\text { grupos }\end{array}$ & $\begin{array}{c}\text { Peso } \\
\text { Relativo }\end{array}$ & Mi & Ei & Idi $^{\star}$ \\
\hline \multirow{3}{*}{$\begin{array}{l}\text { Cor Preta } \\
\text { Cores Claras }\end{array}$} & 3,35 & & $6,54 \%$ & 1 & 1,5 & $5,56 \%$ \\
\hline & 2,74 & & $5,34 \%$ & 1 & 1,5 & $5,34 \%$ \\
\hline & & 6,10 & & & & \\
\hline Quadrado & 2,52 & & $4,90 \%$ & 1 & 1,5 & $6,20 \%$ \\
\hline Cilindrico & 3,81 & & $7,42 \%$ & 1 & 1 & $4,92 \%$ \\
\hline Estojos Convencionais & 3,84 & 10,16 & $7,48 \%$ & 1 & 1 & $5,11 \%$ \\
\hline Couro & 3,88 & & $7,55 \%$ & 0,5 & 1,5 & $4,49 \%$ \\
\hline Plástico & 2,81 & & $5,47 \%$ & 0,5 & 1,5 & $4,65 \%$ \\
\hline Acrilico & 1,87 & & $3,65 \%$ & 1 & 1,5 & $5,99 \%$ \\
\hline Silicone & 3,00 & 11,55 & $5,84 \%$ & 1 & 2 & $7,39 \%$ \\
\hline Aveludado & 4,06 & & $7,92 \%$ & 0,5 & 2 & $4,90 \%$ \\
\hline Tecido & 2,87 & & $5,59 \%$ & 0,5 & 1,5 & $3,37 \%$ \\
\hline Espuma & 2,94 & & $5,72 \%$ & 0,5 & 1,5 & $3,37 \%$ \\
\hline Emborrachado & 3,45 & 13,32 & $6,72 \%$ & 0,5 & 1 & $2,92 \%$ \\
\hline Espelho na parte interna & 3,39 & & $6,60 \%$ & 0,5 & 1 & $2,67 \%$ \\
\hline \multirow{3}{*}{$\begin{array}{l}\text { Bolso para guardar dinheiro } \\
\text { Anexo para lentes de } \\
\text { contato }\end{array}$} & 3,35 & & $6,54 \%$ & 0,5 & 1 & $3,23 \%$ \\
\hline & 3,45 & & $6,72 \%$ & 1 & 1,5 & $5,27 \%$ \\
\hline & & 10,19 & & & & \\
\hline
\end{tabular}

A partir da análise dos dados, identificou-se o índice de importância corrigido pela qualidade demandada e verificou-se algumas diferenças e destaques nas demandas da qualidade apresentadas na Figura 10.

Figura 10: Itens de Importância.Fonte: Os autores (2017).

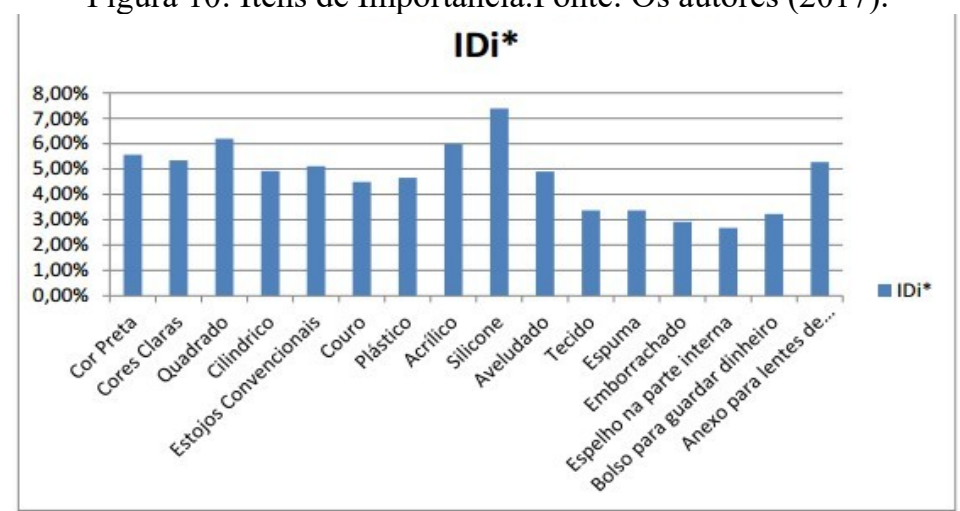

As demandas da qualidade podem ser traduzidas como requisitos dos clientes, assim os itens classificados como mais importantes para os potenciais clientes foram: parte interna com silicone, formato quadrado e de acrílico, anexo para lentes de contato. Entretanto, por motivos viabilidade foi decidido que o material 
interno seria o segundo na classificação de importância, de material aveludado. Partindo dessa análise, a figura 11 apresenta os requisitos e especificações meta de cada item caracterizado como mais importante. Essas especificações meta são características necessárias para atender aos requisitos dos clientes.

Figura 11: Análise dos resultados - Destaque Primário e Secundário.Fonte: Os autores (2017).

\begin{tabular}{|c|c|c|}
\hline $\begin{array}{c}\text { ITENS DOS REQUISITOS DOS CLIENTES } \\
\text { (QUALIDADE DEMANDADA) }\end{array}$ & $\begin{array}{c}\text { REQUISITOS DO } \\
\text { PRODUTO }\end{array}$ & $\begin{array}{c}\text { ESPECIFICAÇOES } \\
\text { META }\end{array}$ \\
\hline Manuseio do Produto & $\begin{array}{c}\text { Formato convencional, } \\
\text { tamanho regular. }\end{array}$ & $\begin{array}{c}15 \mathrm{~cm} \text { de comprimento } \\
\text { O6 cm de largura } \\
08 \mathrm{~cm} \text { de altura }\end{array}$ \\
\hline Cor & Cor preta & Preto convencional \\
\hline Material Externo & Material Couro & Couro sintético \\
\hline Material Interno & Material Aveludado & $\begin{array}{c}\text { Um material de } \\
\text { qualidade e aveludado } \\
\text { para a proteção dos } \\
\text { objetos. }\end{array}$ \\
\hline Funcionalidade & Porta Lentes de contato & $\begin{array}{c}\text { Um porta Lentes de } \\
\text { contato com qualidade } \\
\text { avançada e de } \\
\text { proteção máxima. }\end{array}$ \\
\hline
\end{tabular}

Com os requisitos dos clientes obtidos, foi possível o desenvolvimento do esboço do protótipo do estojo para dois óculos, o então chamado DualCase apresentado na Figura 12.

Figura 12: Protótipo DualCase. Fonte: Os autores (2017).

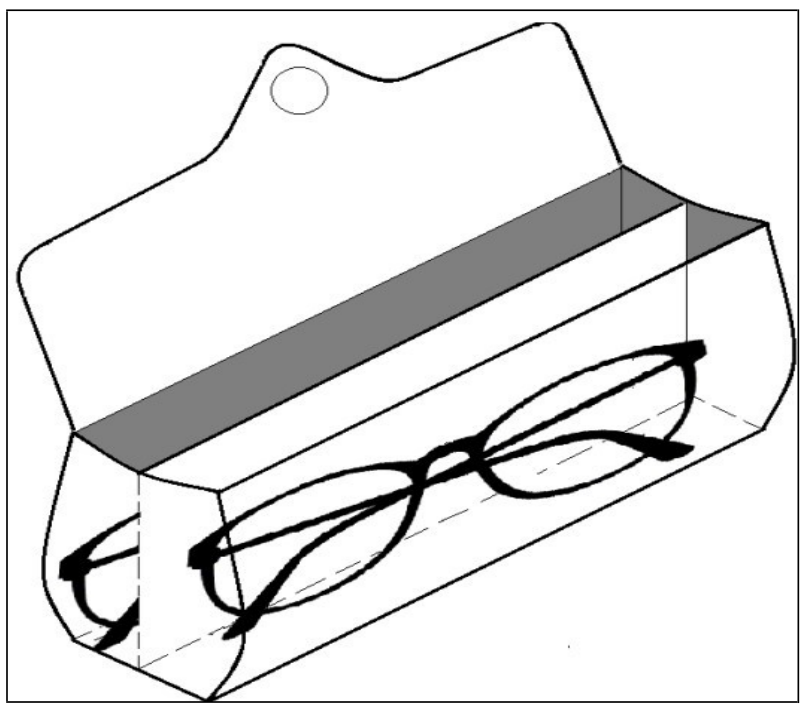

\section{CONCLUSÃO}

O desenvolvimento de novos produtos é uma relevante atividade para as empresas que querem obter vantagem competitiva, porém possui alto risco no sucesso técnico e comercial. O modelo de PDP proposto por Rozenfeld et al. (2006) parte do pressuposto que o sucesso de um produto é consequência do gerenciamento das informações, da equipe e das etapas do PDP. Assim, um fator de sucesso de um produto é a maneira como a equipe gera ideias, decide sobre o desenvolvimento de um novo produto e busca informações acerca dos requisitos dos clientes para traduzi-los em requisitos do produto desenvolvido.

O presente trabalho descreveu as etapas críticas de geração das ideias, definição da escolha do produto a ser desenvolvido, de coleta de informações acerca dos requisitos dos clientes e tradução em requisitos do produto. O que permitiu definir as principais características do produto esboçados em um desenho do protótipo, demonstrando o formato e a usabilidade do produto.

Para isso, foram aplicadas ferramentas como brainstorming, método score, questionários 
qualitativos e quantitativos, a fim de identificar o produto que mais se adeque as necessidades do mercado e recolhendo informações que foram transformadas em especificações meta para o produto, e consequentemente promovesse a satisfação dos clientes.

$\mathrm{O}$ produto desenvolvido trata-se de um modelo de utilidade, que atendeu com êxito o aprimoramento do uso de estojos para acomodar óculos. Tem como público alvo, pessoas interessadas em diminuir espaço em bolsas, ao invés de acomodar os óculos em dois estojos diferentes, o DualCase permite em um único estojo acomodar dois óculos. O projeto do novo produto, elevou a praticidade de carregar com segurança dois óculos em um só estojo.

Por fim, foi analisado que o processo de desenvolver um produto consiste num conjunto de atividades que buscam atender as necessidades de clientes. Seja a melhoria de um produto já existente ou a criação de algo completamente novo. Para que o produto DualCase fosse desenvolvido como planejado, foi essencial a aplicação das ferramentas mencionadas para a aproximação real do que o cliente deseja.

\section{REFERÊNCIAS}

ABRANTES, L.. Brainstorming: Faça uma chuva de ideias! 2016. Disponível em: $<$ http://saiadolugar.com.br/brainstorming/>. Acesso em: 05 jun. 2017.

FREITAS, F. L.; FERREIRA, M. P.; MATSUO, T.K.; FORCELLINI, F.A.; OROFINO, M.

A. R. Processo De Desenvolvimento De Produto: Aplicação Em Um Projeto De P\&D Dentro Do Programa Aneel. XXIV Seminários Nacional de Parques Tecnológicos e Incubadoras de Empresas. Belém-PA. 2014.

GODOY, M. H. C.. Brainstorming. Belo Horizonte: Editora de Desenvolvimento Gerencial, 2001.

ROZENFELD, H.; FORCELLINI, F.A.; AMARAL, D.C.; TOLEDO, J.C.; SILVA, S.L.;

ALLIPRANDINI, D.H.; SCALICE, R.K. Gestão de Desenvolvimento de Produtos: uma referência para a melhoria do processo. São Paulo: Saraiva, 2006.

RIBEIRO, J.L.D.; MOTA, E.V. O desdobramento da qualidade: modelo para services e para manufatura. Porto Alegre: PPGEP, EE/UFRGS, 1996.

TAINO, M. A gestão de Portfólio no Processo de Desenvolvimento de Produtos: estudo de caso de uma indústria alimentícia. 2008. 53 f. TCC (Graduação) - Curso de Engenharia de Produção Mecânica, Universidade de São Paulo, São Carlos, 2008. 